\title{
Philosophical pitfalls in cosmetic surgery: a case of rhinoplasty during adolescence
}

\section{T Hilhorst}

In the process of deciding to undergo cosmetic surgery for aesthetic reasons, people may err in various ways. Adolescents in particular run the risk of making errors, and both parents and surgeons have special moral responsibilities to avoid disappointments. Parents should face a number of moral issues; if they fail to do so, surgeons have the moral if not legal responsibility, to raise these issues and take a moral stand.

In this paper, a number of piffalls are specified from a philosophical perspective. A request for surgery should not be granted if patients do not meet the standards required for stable decision making and a balanced judgment, and particularly in those cases where patients fail to understand the assumptions - in terms of human values-underlying the surgical intervention. Assessments of competence should go beyond formal conceptions of autonomy, and should, as will be shown, be made on an individual basis. Substantive questions of personal identity and identity formation, within the context of often rapid psychosocial development and emotional turmoil peculiar to adolescents, should be addressed. The key to the moral evaluation of this surgery therefore lies primarily in a patient's life story.

Correspondence to: Dr M T Hilhorst, Department of Medical Ethics, Faculty of Medicine and Health Care, Erasmus University, PO Box 1738, 3000 DR, Rotterdam, The Netherlands; hilhorst@ feg.fgg.eur.nl Rotterdam

Accepted for publication 1 August 2002
$\mathrm{S}$ uppose that my 17 year old daughter tells me about her plans to have a nose correction (rhinoplasty) for cosmetic reasons. She has been working in America as an au pair, and has seen good results obtained by a friend. My daughter believes her nose is too long and pointed. A surgeon has ensured her that nose correction is a real option for her. As a mother, I am not inclined to dissuade her after all, we are liberal minded, aren't we? But, to be honest, I have my doubts. There are at least a few things I want to talk through with her.

I would advise her to see the best surgeon. Not only does she deserve good results, but I also expect from a good doctor that ( $\mathrm{s}$ ) he will discuss matters extensively with my daughter, to help her underpin her decision and weigh the benefits, burdens, and risks. It is not that I do not trust my daughter's judgment; I take her judgments as seriously as my own. She is a strong young person who has arrived at an age at which she should take things into her own hands. We can discuss things as equals, but she may err; if she does, I would like to dissuade her from carrying out her plans by pointing out to her the weaknesses and fallacies in her judgment. I expect from a doctor that (s)he will act accordingly.
What, then, do we need to discuss? And how? To start with, we should squarely face all the potential risks of making an error in judgment. A person can err in various ways and, if her judgment is based on unthinking or short sighted considerations, she may sooner or later regret her decision. At least five issues therefore deserve our attention and may constitute pitfalls: (1) the perception that she is a stable decision maker; (2) the idea of surgery as a technique to produce a pleasing appearance; (3) her view on the importance of bodily beauty; (4) the process of balancing pros and cons, and (5) the past, when seen as an inherent part of her future life.

\section{A STABLE DECISION MAKER}

Given the fact that the nose operation is hardly reversible, her wish should be stable over time. The cosmetic correction cannot be undone easily; her choice should therefore not be a whim. But the life of a young girl is prone to changes in fashion: her models for beauty today will almost certainly not be those of tomorrow. Moreover, choices are strongly influenced by external factors, such as friends and the media. In addition, personal feelings of reduced self confidence play an important role. At this age young girls often feel insecure about who they are and who they would like to become. It would be a mistake to think that the immediate satisfaction they may feel after the operation justifies the surgery itself. Benefits should be assessed in a more comprehensive way, and over a longer period of time. A girl's judgment may easily change over time. She may regret her decision later, or after many years she may perceive her choice for a bodily change, made when she was young, as shallow or mistaken. In those cases her wish would appear to be transient. Presumably she will say: "It was not my own, not really my decision at that time. My friends, fashion, and other circumstances influenced my decision too greatly. But, even more importantly, I myself didn't really know what I wanted." These statements are probably all true: with time, her wishes changed, her views changed, and she has changed.

Many girls make choices in situations in which their young personal identity is still developing: this, of course, is not a solid basis for drastic decisions. Parents are therefore inclined to assume the decision making process on their child's behalf: "Aren't you too young for this? Are you sure your wish is mature enough? Do you realise that your decision may substantially affect your life over time?" A mature wish presupposes a wise, mature person. To say that someone is making an autonomous decision presupposes a "someone" - that is, a person who is capable of leading a life of her own. ${ }^{1}$ It would be a mistake to see oneself as mature and to find out later that 
one wasn't. She-along with her parents and her doctorshould reflect on what it means to be mature enough to make a stable decision over time. ${ }^{2}$ The ultimate point of reference for a doctor cannot be a mere preference expressed by a patient. Neither can perceived autonomy be of much help. A doctor cannot shrug his or her shoulders and say: "Apparently this is what she (at this moment) really wants".

Behind the concept of autonomy and the ensuing criteria for competence lie ideas about what it means to be a person, and to be an autonomous and competent decision maker. Each self willed decision requires good reasons, yet those good reasons are embedded in a person's life story. What is good for one person is not necessarily good for another. A life story reflects the type of person one is and aspires to become. The more deeply rooted the judgments are in this person's life story, the more stable they will presumably be. A personal life story will, of course, change over time: new experiences will be added to, and new insights incorporated into, what is called a person's "identity". ${ }^{4}$ Over time, the narrative concept of personal identity-more so than the concept of autonomy-can better account for this dynamic process and provide a better basis for the evaluation of good decision making. To change and to strive for change is a basic characteristic of being a person. Personal identity should not be conceived of as fixed or invariable. No one remains unchanged over time, not even in a physical respect (apart from one's characteristic DNA). Yet, in another sense, one also remains the same person over time. One characteristic of being a person is that lifelong experiences are, in one form or another, constantly being processed and integrated. Deep inside, we believe, there is someone who can say "I". Here we expect to find some consistency of motivations, coherence, and durability of considerations, and a continuity of judgment over time. It is precisely this often complex personal story which should serve as a basis for the assessment of the authenticity of a person's wishes.

It would be a mistake to think that it is not necessary to talk with a person seeking cosmetic surgery about the deeper roots of what it is she wants. It is important to see whether she is capable of telling a story of her own, and can explain which personal experiences and fundamental insights form the core elements of this story. Her story can articulate the firmness of her personal identity. Without that, she lacks some of the solid basis necessary for stable decision making and well balanced judgment.

\section{SURGERY AS A TECHNIQUE TO PRODUCE A PLEASING APPEARANCE}

We should also pause to reflect on the surgery itself. My daughter's view of it may be flawed. Her wish to use this technique to produce good cosmetic results presupposes value judgments. Is she aware of that? We all know that bodily beauty can be achieved by many means. It would be a mistake to confuse them. ${ }^{5}$

Good results can, for instance, be achieved through adornment. In accordance with our daily wishes, we change clothes, apply make up, and put on jewellery. By these means we can bring about various forms of bodily beauty, and thereby express a distinct personal charm. Adornment is what many people, and not only the young, enjoy as an everyday activity. It presupposes flexibility. It allows us to switch easily between ideas of beauty, and to experiment with them. We can play with our bodily looks and personal appearance by hiding the parts we don't like and revealing what we like most. We express not only preferences: our manners may indeed reflect complete lifestyles. Consider the effort we often put into activities such as fitness and dieting, to improve our bodies' appearance. These practices may go far beyond a mere preference or fleeting fashion. They reflect particular lifestyles quite essential to our lives. Like piercing, and tattoos, clothes, make up, and jewellery can be part of a lifestyle that is constitutive for one's identity.
By contrast, cosmetic surgery is a different technique with regard to its nature, range and impact. By its nature, it has advantages and disadvantages. Results can be achieved that can never (or hardly ever) be accomplished otherwise. Yet the technique does not allow for flexibility. It aims to achieve its own, strictly defined idea of a pleasing appearance, and accordingly results in a fixed bodily shape. We cannot experiment with it as we can with body decoration and adornment. The construction of a specific, physiological image is, by definition, its sole end. Moreover, the technique itself tends to minimise a patient's own role in achieving that end: one must put one's life into a surgeon's hands. It also has its own range, which does not embrace personal appearance in a wider sense. The technique is restricted to the physical body as such. This surely is different from other techniques or endeavours. With the use of make up and earrings, or by a change of hairstyle, one can, for instance, draw attention away from a long and pointed nose. One can emphasise other bodily features, or give the nose a better, more fitting context. Cosmetic surgery, on the other hand, can only accommodate the wish for change in physical terms, and provide an answer in kind. Because it is inherently restricted to the body, the technique has its own implications. It produces permanence and invariability. Only one view of physical appearance is implemented, and one is forced to concur that one specific shape of nose, ears, breasts or, legs, etc is better for you than another. Cosmetic surgery provides only one physical shape, with fixed specifications and one view as to what represents a good cosmetic result.

I hope that my daughter understands the spirit of cosmetic surgery. The cosmetic ends she has in mind for herself may justify the surgical means. She should realise, however, at what cost -in terms of personal values and philosophies of life-this may be accomplished. Her choice for surgery may, by implication, (1) rule out other views of bodily appearance, (2) set aside other means of achieving beauty, and (3) preclude other ideas about personal identity and lifestyles, and her own role in shaping them. These are implications of which she should at least be aware.

\section{BODILY BEAUTY}

My daughter should also reflect on the value judgments with respect to beauty implicit in her wish for a nose correction. She is, of course, aware of the fact that surgery will lead to her face taking on a new, fixed shape. But, she says, this is precisely what she wants. She simply deems it an improvement. She also assures me that it is not a whim, and reminds me of the fact that her nose has been bothering her for a long time. According to her, everybody ("nine people out of ten") can see that her nose is too long and pointed, and not beautiful. This, she argues, is an almost objective and incontestable value judgment that no one can contest. The burden of proof lies with me: "Why shouldn't one make use of techniques that provide a better shape for a nose which most people see as disproportional?" I feel, however, that a number of assumptions are hidden behind this judgment, and I ask her to talk about the sense in which she considers the new shape an improvement. What does she mean by "better"; which view of bodily beauty leads her to this judgment? I encourage her to look more closely into the story of her life. What good for her is linked to this "better shaped" nose, and what does physical beauty mean to her, what place does it have in her life? Meanwhile, I also feel compelled to reflect on my own views and assumptions.

I agree with her that aesthetic distinctions can be drawn between beautiful bodies and bodily parts and those that are less beautiful. Some people are indeed more beautiful than others, and have, more particularly, beautiful hair or legs, a beautiful face or bodily shape. Tastes may differ considerably, of course, but aesthetic judgments are not purely subjective. Our judgments are based, for instance, on considerations of 
harmony, symmetry, and proportionality. ${ }^{6}$ Precisely these aesthetic norms enable her and her surgeon to reach agreement on the new shape of her nose.

Now let us suppose that the surgeon creates exactly the nose she wishes. In an objective sense, therefore, the doctor has done a fine job. But does this also imply that, after the operation, my daughter will enjoy the nose and accept it as her own? Not necessarily, because physical fact and logic are not the only factors of importance. ${ }^{7}$ There is also a mental side to the story. The physical change should be accompanied by an appropriate mental change, and at this point, too, she may err. Can she be sure that her feelings-for example, her sense of identity, will adjust to her new looks? What makes her think these mental changes will follow as a result? This is not an objective matter, of course, but an individual issue that requires reflection from an internal, personal point of view.

It would be a mistake to think that, with respect to the body, one can adopt a purely external stance. Body and mind are not two separate areas of human life; they come together in the person one is. The ability to cope with both, by harmonising them, is not simple, straightforward, or self evident. The mind never reigns over the body completely, nor does the body rule the mind. A certain dynamic tension between them is to be found in every human being. When we consider operating on the body, we must try to understand the often complex interactions with the mind. Some people are quite unhappy with the results of an operation, even though the surgeon has accomplished what they had demanded. Other people exhibit a new dissatisfaction with other parts of their body. A person's mental side may be tested even more sorely when the surgeon is not able to create exactly the desired shape, and when the result turns out to be somewhat less than satisfying. Would my daughter be able to cope with such a situations? Does she know herself well enough in this respect?

Before she decides to have the operation, she must reflect upon how much she can bear or withstand. Moreover, in addition to whatever tasks the surgeon assumes, she must do her own "mental work". One's ability to cope is a mental task, and has strongly individual characteristics. It is not easy to predict whether an operation will result in satisfaction or sorrow. Obviously, complex and considerable differences may exist between different people. Without real mental toughness tied to a desperate desire for this and only this new nose, there will be a very real chance that she could regret her decision later. If, however, she is not too fixated on one exclusive idea of a good nose, and if she is prepared to accept the result, even if it is not exactly the perfect result she had in mind, there is a good chance that she may indeed benefit from it. Remarkably enough, for some people the mere fact that they have taken control of their lives is enough to make them feel good about the surgical intervention, regardless of its result. It is therefore important that plastic surgeons work closely with psychologists. Psychology can shed light on our psychological make up and the mental mechanisms at work in us. Psychology can also teach us how to use our capabilities to handle them, how to be the master of our thoughts and feelings with regard to our bodies, and how to deal with that which remains beyond our control.

One would, however, be mistaken to think that this is solely a psychological matter which does not involve the philosopher (or the surgeon). One cannot simply equate "mind" with psychology. The question of how to live and how to deal with suffering or unhappiness with respect to one's bodily appearance presupposes, again, a view of what it is to be a person and live a life of one's own. My daughter has to learn to live with her "self", be it her "new self" after an operation or her "old self" when she refrains from surgical intervention, and this is something which we all have to face in some way or another. It is part and parcel of the human condition, a fundamental and unavoidable fact. It summons up deep existential and philosophical questions, and answers should therefore be given at that same level. What answers will my daughter give? These should be looked for in terms of life stories reflecting her personal identity-for example, with regard to her body and mind. ${ }^{8}$

In short, we cannot regard personal appearance and bodily change as an external issue. It is, rather, an issue that requires reflection on both body and mind and their often complex relationship. This reflection should take place "from within", and touches on questions which are existentially and philosophically fundamental for one's life. ${ }^{9}$ Some decisions are more vital and deeper than others. At my daughter's age, bodily change may be one of the more vital decisions about which one can have doubts, along with others such as the decision to undergo sterilisation, to become a nun, to have a child, or to emigrate permanently to a different land and culture. They are vital because they will essentially affect the decision maker in terms of his or her personal identity. Such decisions therefore cannot stand on their own, but should be assessed in a broader and deeper sense.

\section{THE ACTUAL PROCESS OF BALANCING}

Let us assume that my daughter greatly desires this "new look". If it were not important to her, after all, she wouldn't be willing to discuss it at such length. In the Netherlands, at least, a considerable threshold must be crossed by many women wishing to see a doctor for cosmetic reasons. But how, in actual practice, can life stories serve as the basis for good decisions and critical assessments? How can a personal identity do its work "in action"?

I agree with my daughter that physical beauty is a value in its own right, and that it does matter. But should it have the weight she gives it, or should it be balanced by other values? If you ask me, it is hard to see her nose as a separate issue, and to make value judgments about it independently of the person to whom that nose belongs. If we judge the beauty of a person's nose, we inevitably judge her as a person as well-how she looks, speaks, and behaves, talks, and how she lives her life as we know it. My daughter's nose has, so to say, a context: that context is the person of my daughter. Her many features contribute to a more complete judgment concerning the person she is. Although we can certainly zoom in on her nose and judge it, we inevitably take into account, I think, its context. Those who meet her will see her nose as part of a bigger picture. "For me, this is You, with your nose. There is no other You. Friends take your nose as a given, inseparable part of you. So, why does your nose bother you so much that you would consider changing it?"

My daughter agrees that physical beauty is a complex thing. How one feels about it is very much a personal thing. ${ }^{10}$ Moreover, it is complex because personal and unique circumstances play an important role in it. When she explains to me the place her nose actually assumes within her life story, she inevitably points to this wider context and talks about her views and expectations.

"There are periods", she says, "when my nose bothers me. Then this nose 'gets in the way' between me and other people. My nose is on my mind and keeps me preoccupied. I'm particularly aware of it when I meet new people, more than when I'm with old friends. Surgery would fit into this moment in my life, now that I'm leaving secondary school and starting a new life at a college somewhere else.

"At other times," she admits, "it doesn't keep me particularly preoccupied, but when I look in the mirror I realise then too that my nose is less than attractive. My desire to correct it is not inspired by girlish motivations, nor by a desire to be more perfect or beautiful than others, but by the desire to feel more normal. ${ }^{10}$ My motivation is simply that I want to make use of my opportunities in life and to seize the chance to change my nose now that there's an opportunity to do so. I am very well aware that there are other values more essential in 
life; physical beauty is merely one value of some importance, and for me only of relative weight.

"Therefore", she continues, "I don't believe a changed nose will alter Me, the person I am, at least not essentially. My dealings with other people may become more relaxed and less troubled by thoughts about myself. I may feel more self confident, less constrained." Then, she concludes: "Of course something will change in my relation to others, although it is hard to say what and to what extent".

Her explanation is an interesting one. What she wants is a comprehensive change, not just in a physical sense, but also in a personal and social sense: changes in feelings, thoughts, attitudes, and behaviour, both within herself and with regard to others, and also the other way around-of others towards her. She is consciously aiming for these changes, and hopes and expects them to materialise. These expectations and their fulfilment play a crucial role. If her wish is strongly influenced by external factors (friends) or by internal factors (a lack of self confidence), the operation's success depends primarily on the lasting effect it will have on these factors: will there actually be a change in the direction she expects and wants so desperately? Do her new looks indeed contribute to greater self respect and self confidence; do her friends or the people she meets respond in the way she hoped; is she less troubled by her appearance; does she indeed have a more relaxed social life; does she feel that her chances in life have improved?

What I ask her is: what reason does she have to believe that all this will be accomplished, and what if it all falls short of her expectations? Will she be able to overcome her disappointments? Some people react to cosmetic surgery with an even stronger focus on their appearance and their troubles with it; others express rising expectations, and the wish to have more surgical interventions. My daughter is both intelligent and prudent but she may need other capacities as well: flexibility, the ability to put things in perspective, to deal with emotions, to assign a place in her life for all kinds of experiences, and the ability to overcome the many difficulties life may bring. This goes far beyond the traditional ethical question of how one goes about weighing burdens and benefits. It encompasses achieving a balance between one's life as such and one's fragile identity. It requires the harmonising of expectations with reality. A stable decision requires, at some point, satisfaction with the person one is and the acceptance of what has been accomplished. It requires the gradual development of a stable and authentic "I". If my daughter is not aware of this, her wish for a surgical change may turn out to be a grave mistake. If her expectations are unrealistic and her ends unachievable, I point out to her, cosmetic surgery is hardly a good means to choose. In short, she must find a balance between her expectations and that to which she can realistically aspire. She must be honest with herself about what cannot be accomplished. She must face that side of the human condition which cannot be changed or is beyond her control. She must face the fact that a body cannot always be constructed in the way we would like, and that life cannot always be planned. To disregard this would be a serious and potentially costly mistake. ${ }^{11}$

Who knows how people will respond to my daughter after an operation? There is no guarantee that the changes she hopes for will actually be achieved This is, in part, beyond her control. The interaction between her new self, as she sees and experiences it, and others is a complex one. She can only try to think ahead about what can happen with her, to understand the complexities of the changes, and to be aware of the possible impact of such a seemingly simple and minor bodily change as a nose correction. It can be helpful in this context to recall the normative model of the "real life test" used for transsexual operations. Before an operation is performed, a person has to live for some time as though he has been transformed-for example, he wears the clothes and otherwise adopts the appearance of the desired gender, in order to find out more about his own feelings and the reactions of others. ${ }^{12}$ If we apply this-either in real life or virtually, as a thought experiment-to cosmetic interventions, we must picture ourselves as living with new (but reversible) artificial breasts, ears, lips, or nose, and imagine our feelings towards the reactions of others.

Much ethical thought springs from such experiments: we put ourselves in other people's shoes and expectreciprocally-them to do the same. We then realise that people are constantly being qualified by others on the basis of their features, and often are labelled accordingly: as transsexual, gay, woman, patient, doctor, slim, fat, lazy, smart, etc. We listen to their stories, share their experiences, reflect on what it means to live these lives and try to be honest about our own life. From this perspective we contemplate our own qualities, reflect on personal choices such as change in bodily appearance, and seek to live authentically. Of course, no one-if they have a choice-is likely to choose a less pleasant life, or a body that will be a burden to them. But once given that body, can we simply leave it behind and trade it in for a new life?

My daughter is frank. "I don't need a real life test, I've seen the results achieved by a friend of mine, with whom I have much in common. All I expect from the change is greater confidence in myself, fewer distractions caused by my appearance, a feeling of greater control, a feeling of being 'more me'. And my friends will also see 'more me', me as I really am, and will be happy for me. What has always been 'in me' will become public: I will be more open, more spontaneous, more willing to show my emotional self, etc. Those who knew me before will, in due time, take my bodily change for granted, I suppose. And those I have yet to meet will accept me perfectly as the one I am at that point. I will, of course, never want this old nose back."

Her expectations are indeed high. But are they realistic and well balanced, or are they too high? I convince her to do one more thing: to listen to some stories of girls who have, in fact, been disappointed after their operations, and to some women who look back on the bodily changes they underwent years ago, when then were young.

\section{LIVING WITH THE PAST}

"Suppose," I ask her to imagine, "you get a new boyfriend; will you tell him about your physical past? Will you show him old photographs, or are you going to destroy them all? Will you like being reminded of your past?" She responds promptly: "Why not? I'm strong enough, I have nothing to hide." I suggest that she may be taking a risk. Her future friend may be disappointed when he hears about her past, even when she has told him of her reasons for the surgical change. He may say he would have tried to dissuade her from having the operation; that he doesn't consider her old looks unattractive; that he is even somewhat hurt by the knowledge that her present appearance is manmade, constructed, and artificial. ${ }^{13}$ What he sees and feels is not natural, but constructed beauty. "Are you willing to take that risk, or would you-on second thought hide the facts from him?" She sticks to her first response: "That would be his problem; he has to take me as I am, and as I was", she says, "including my former looks, which I changed, I think, for good, stable reasons."

I admire her openness. Her "new self" will have to live with her "old self", including her bodily past. This past not only encompasses her former looks, but also her former choices. She will be a stronger person if she is aware of this and open about the reasons for her decision. "It would be a mistake," I agree, "to think that you can leave your past behind. From time to time you will be confronted with it; you should mentally be prepared for that. A bodily correction does not automatically make your life easier. Your past is part of you, and should become part of your life story. Be aware of that." 
She replies: "If my new friend respects me, he will also respect my choices. He may even be proud of me for having taken control of my own life. What counts is my actual self, as it has developed. There is no reason to forget the past. But it is only that: the past."

\section{IN CONCLUSION}

My daughter says our talks have not only given her more clarity about the nature of the surgery and her ideas about physical appearances, but also about herself. Whatever she decides, she now feels the challenge to become a mentally stronger person, more deeply rooted in her bodily self.

"Talk more about it," I advise her, "with the surgeon, with your friends, with whomever you meet. And above all, with your father. After all, the nose you're not pleased with is one you inherited from him." Her surgeon has the professional and moral duty to talk and listen to her in this way. Will the surgeon come to the conclusion that my daughter's wish is really stable and authentic - that is, deeply rooted in her life as she maturely chooses to live it? If not, then the surgeon should refrain from carrying out the operation. Although philosophy cannot make choices for individual persons, it can, as we have seen above, contribute to self reflection and decision making.

\section{ACKNOWLEDGEMENT}

This research is part of a European BIOMED research project, Beauty and the Doctor, coordinated by the Rotterdam Department of Medical Ethics.

\section{REFERENCES}

1 Flanagan O. Self-expressions: mind, morals and the meaning of life. New York: Oxford University Press, 1996.

2 Simis KJ, Koot JM, Verhulst FC, et al. Assessing adolescents and young girls for plastic surgical intervention: pre-surgical appearance ratings and appearance-related burdens as reported by adolescents and young adults, parents and surgeons. British Journal of Plastic Surgery, 2000;53:593-600; Simis KJ, Verhulst, FC, Koot HM. Body image, psychosocial functioning, and personality: how different are adolescents and young adults applying for plastic surgery? Journal of Child asychology and Psychiatry, and Allied Disciplines 2001;42:669-78.

3 Buchanan AE, Brock DW. Deciding for others: the ethics of surrogate decision making. Cambridge: Cambridge University Press, 1990: chs 1 and 5 .

4 Schechtman M. The constitution of selves. Ithaca: Cornell University Press, 1996.

5 Parens E. Is better always good? The enhancement project. Hastings Center Report 1998; Jan/ Feb(suppl); Parens E, ed. Enhancing human traits: ethical and social implications. Washington: Georgetown UP, 1998.

6 Marwick A. Beauty in history: society, politics and personal appearance. Gloucester: Thames and Hudson, 1988.

7 Ginsborg H. Kant on aesthetic and biological purposiveness. In: Reath A, Herman B, Korsgaard Chr M, eds. Reclaiming the history of ethics. Cambridge: Cambridge University Press, 1997: 329-30.

8 Lansdown R, Rumsey N. Visibly different: coping with disfigurement. Oxford: Butterworth/Heinemann, 1997.

9 Partridge J. Changing faces: the challenge of facial disfigurement. London: Penguin, 1990.

10 Davis K. Reshaping the female body: the dilemma of cosmetic surgery. New York: Routledge, 1995.

11 Halprin S. "Look at my ugly face": myths and musings on beauty and other perilous obsessions with women's appearance. New York: Viking Penguin, 1995.

12 Gooren LJG, Doorn CD. What is medically necessary and what is needed in some other sense? The case of transsexual operation. In: Beaufort I de, Hilhorst M, Holm S, eds. In the eye of the beholder: ethics and medical change of appearance. Copenhagen: Scandinavian University Press, 1997: 15-25.

13 Hilhorst MT. Physical beauty: only skin deep? Medicine, Health Care and Philosophy 2002;5:11-21. 